\title{
Op welke leeftijd wordt hydrocefalus ontdekt, en wat is de rol van hoofdomtrekmetingen?
}

Het doel van deze studie was te onderzoeken op welke leeftijd hydrocefalus in Nederland wordt ontdekt, en wat de rol van hoofdomtrekmetingen is bij het ontdekken van hydrocefalus. Hiertoe is een retrospectief statusonderzoek verricht bij kinderen die zijn behandeld voor hydrocefalus in een tertiair kinderziekenhuis in Nederland. De studiegroep bestond uit 146 patiënten. Van de 122 patiënten van wie de reden voor verwijzing bekend was, werden 38 patiënten (31\%) verwezen vanwege bijzonderheden in de hoofdomtrek. 89\% (95\%-BI: 82-93) van de patiënten werd ontdekt in het eerste levensjaar. Na het eerste levensjaar werden geen patiënten verwezen vanwege bijzonderheden in de hoofdomtrek. Het merendeel van de patiënten werd ontdekt om andere redenen dan een afwijkende hoofdomtrek. Hoofdomtrekmetingen lijken weinig waarde te hebben voor het opsporen van hydrocefalus na het eerste levensjaar.

Dit artikel is een vertaalde en aangepaste versie van de volgende publicatie: At what age is hydrocephalus detected, and what is the role of head circumference measurements? Jacqueline $M$. Breuning-Broers, Jacqueline A. Deurloo, Rob H. Gooskens, Paul H. Verkerk. Eur J Public Health. 2014 Feb;24(1):32-34. doi: 10.1093/eurpub/ckt101

\section{Inleiding}

Hydrocefalus is een aandoening waarbij er een abnormale ophoping is van cerebrospinale vloeistof in het hoofd. Deze kan worden veroorzaakt door diverse aandoeningen (zoals aqueductstenose of hersenbloeding). Hydrocefalus kan zowel aangeboren als verworven zijn. De prevalentie van hydrocefalus wordt geschat op 1,5 tot 5 per 10.000 levend geborenen., ${ }^{1,2}$ Hydrocefalus kan leiden tot een abnormaal groot hoofd of een snelle toename in hoofdomtrek. Tegenwoordig wordt een groot deel van de kinderen met een aangeboren hydrocefalus ontdekt bij prenatale echografie. Het is niet duidelijk wat de rol van routinematige hoofdomtrekmetingen is bij het opsporen van kinderen met een hydrocefalus. In een Noorse studie concludeerden de auteurs dat de meeste kinderen met een toegenomen hoofdomtrek veroorzaakt door intracraniële groei worden ontdekt in de eerste levensmaanden. ${ }^{2}$

Het doel van onze studie was te onderzoeken op welke leeftijd hydrocefalus in Nederland wordt ontdekt en welke rol hoofdomtrekmetingen bij de ontdekking van hydrocefalus spelen.

In Nederland komen kinderen tot vier jaar ongeveer 13 keer bij de jeugdgezondheidszorg. De hoofdomtrek wordt bij ieder bezoek gemeten tot de leeftijd van één jaar (in totaal circa acht keer). Deze metingen worden ingevuld in groeicurven voor de hoofdomtrek naar leef- tijd. ${ }^{3}$ Op dit moment zijn er in Nederland geen officiële verwijscriteria voor hoofdomtrek. Sommige andere landen (Noorwegen, Canada, Verenigd Koninkrijk) hebben deze wel, maar deze zijn niet evidencebased. 2,4,5 Meestal worden kinderen in Nederland naar de huisarts verwezen als de hoofdomtrek > 2,5 standaarddeviatiescores (SDS) is of als deze twee percentiellijnen doorkruist. De huisarts verwijst meestal door naar een kinderarts of kinderneuroloog.

\section{Methode}

Met behulp van het ziekenhuisinformatiesysteem (ZIS) van het Wilhelmina Kinderziekenhuis (WKZ) te Utrecht selecteerden wij alle kinderen geboren tussen 1 januari 1975 en 31 december 2005 met de diagnose 'hydrocefalus'. Kinderen met een neuralebuisdefect werden geëxcludeerd.

We verrichtten een retrospectief dossieronderzoek bij alle overgebleven kinderen. De volgende variabelen werden geregistreerd: geslacht, geboortedatum, zwangerschapsduur, geboortegewicht, verwijsdatum, eerste verwijzende arts, verwijsreden, datum eerste bezoek ziekenhuis en diagnose gesteld in het WKZ. Voor de analyse werd gebruikgemaakt van SPSS versie 17.0.

\section{Resultaten}

\section{Studiegroep}

We vonden 203 kinderen met de diagnose 'hydrocefalus' Er werden 57 kinderen geëxcludeerd, omdat van hen te veel gegevens ontbraken, zodat er 146 kinderen in de studiegroep zaten. De studiegroep bestond uit 72 jongens (49\%) en 74 meisjes (51\%). $31 \%$ van de patiënten was prematuur geboren ( $<37$ weken) en $33 \%$ had een laag

J.A. Deurloo, jeugdarts KNMG, wetenschappelijk medewerker, TNO Child Health, Leiden, GGD Hollands Noorden, Schagen. J.M. Breuning-Boers, kinderarts n.p., TNO Child Heaith, Leiden. R.H. Gooskens, kinderneuroloog, Rudolf Magnus Instituut voor Neurowetenschap, afdeling Neurologie en Neurochirurgie, Wilhelmina Kinderziekenhuis Universitair Medisch Centrum, Utrecht. P.H. Verkerk, arts Maatschappij \& Gezondheid, TNO Child Health, Leiden, Correspondentie: paul.verkerk@tno.nl. 
geboortegewicht ( $2500 \mathrm{~g}$ ). De meerderheid van de patienten was verwezen door een gynaecoloog $(30 \%)$, kinderarts $(32 \%)$ of jeugdarts (19\%). De resterende patiënten waren verwezen door andere professionals (huisarts, fysiotherapeut, neuroloog); van 17 patiënten (12\%) was de verwijzer niet bekend. Bij $34 \%$ van de patiënten werd de hydrocefalus veroorzaakt door een aqueductstenose.

\section{Reden voor verwijzing}

De reden voor verwijzing was genoteerd bij 122 patiënten. In dit onderzoek werd alleen de belangrijkste verwijsreden geanalyseerd. 43 patiënten (35\%) waren verwezen vanwege bijzonderheden tijdens echografie gedurende de zwangerschap of kort na de geboorte, 38 patiënten

\section{Situatie in Vlaanderen}

In Vlaanderen worden kinderen van nul tot 2,5 à drie jaar gezien door Kind \& Gezin. Gedurende deze periode zijn er minimaal twee huisbezoeken en tien basisconsulten bij een consultatiebureau (CB). Bij elke gelegenheid wordt de hoofdomtrek van het kind gemeten. In een nieuwe groeimodule (die sinds 1 april 2014 in het elektronisch kinddossier is opgenomen) wordt een automatische verwijzing naar de behandelend arts aanbevolen in geval van:

1. vaststelling van een hoofdomtrek groter dan $-2,5$ SD of kleiner dan $+2,5$ SD of

2. een verschil ten opzichte van een eerste meetwaarde bij Kind \& Gezin kleiner dan 2 SDS of

3. wanneer de conditionele groeisnelheid (dit is de groeisnelheid gecorrigeerd voor de uitgangspositie) tijdens twee opeenvolgende periodes groter dan 1 SD of kleiner dan -1 SD is.

Wanneer de conditionele groeisnelheid voor het eerste groter is dan 1 SD of kleiner dan -1 SD, kan de arts besluiten tot doorverwijzing op basis van anamnese of klinisch onderzoek of wordt een controlemeting na één maand op het $\mathrm{CB}$ aanbevolen. In geval van anamnestische of klinische tekenen van overdruk kan de $\mathrm{CB}$-arts steeds op eigen initiatief doorverwijzen. Conditionele groeinormen zijn slechts voorhanden tot en met de leeftijd van 24 maanden.

Voor de schoolgaande jeugd verzorgen de Centra voor Leerlingbegeleiding (CLB) de preventieve jeugdgezondheidszorg. In de CLB wordt gebruikgemaakt van de 'Standaard groei en pubertaire ontwikkeling. ${ }^{6} \mathrm{De}$ hoofdomtrek wordt eenmalig gemeten, bij voorkeur bij de start van de schoolcarrière, dat wil zeggen: op de leeftijd van drie à vier jaar. In de standaard staan geen concrete verwijscriteria voor de hoofdomtrek. Er wordt geadviseerd om bij macrocefalie (hoofdomtrek > P97) een verwijzing te overwegen, afhankelijk van de voorgeschiedenis en het ontwikkelingsniveau van het kind.
(31\%) vanwege bijzonderheden in de hoofdomtrek en 41 patienten $(34 \%)$ vanwege andere symptomen. Van de patiënten die waren verwezen vanwege bijzonderheden in de hoofdomtrek, werden er $32(84 \%)$ gesignaleerd in de eerste zes levensmaanden (tabel 1).

Leeftijd

Van 54 patiënten was de leeftijd ten tijde van verwijzing niet bekend. Voor deze patiënten gebruikten we de leeftijd bij het eerste bezoek aan het WKZ of de start van de behandeling als een schatting voor de leeftijd bij ontdekking van hydrocefalus. Bij 12 patiënten was de leeftijd bij verwijzing niet te bepalen. In tabel 1 is de leeftijd bij ontdekking van hydrocefalus weergegeven: bij $89 \%$ (95\%BI: 82-93) van de patiënten was de hydrocefalus ontdekt in het eerste levensjaar.

Slechts bij 15 patiënten was de hydrocefalus ontdekt na het eerste levensjaar. Geen van deze patiënten was verwezen vanwege bijzonderheden in de hoofdomtrek. De verwijsredenen bij deze 15 patiënten waren: hoofdpijn, ontwikkelingsachterstand, visusproblemen en epilepsie. De meest gestelde diagnoses bij deze 15 kinderen waren aqueductstenose en communicerende hydrocefalus.

Patiënten verwezen door de jeugdarts

$28 / 146$ patiënten (19\%) waren verwezen door de jeugdarts. De meest voorkomende verwijsreden was een afwijkende

Tabel 1 Leeftıjd bij signalering van hydrocefalus bij patiënten die werden verwezen op basıs van hoofdomtrek $(n=38)$ en voor alle patienten $(n=134)$

\begin{tabular}{|c|c|c|c|c|}
\hline \multirow[b]{2}{*}{ leeftijd } & \multicolumn{2}{|c|}{$\begin{array}{l}\text { patiënten verwe- } \\
\text { zen op basis van } \\
\text { hoofdomtrek } \\
(n=38)\end{array}$} & \multicolumn{2}{|c|}{$\begin{array}{l}\text { alle patiënten } \\
(n=134)\end{array}$} \\
\hline & $n$ & $\begin{array}{l}\text { cumula- } \\
\text { tief } \%\end{array}$ & $n$ & $\begin{array}{l}\text { cumula- } \\
\text { tief } \%\end{array}$ \\
\hline 0 - 2 dagen & 8 & 21 & 61 & 46 \\
\hline 3 dagen - 1 maand & 4 & 32 & 9 & 52 \\
\hline 1- 2 maanden & 3 & 40 & 8 & 58 \\
\hline 2 - 3 maanden & 4 & 50 & 10 & 66 \\
\hline 3- 4 maanden & 6 & 66 & 9 & 72 \\
\hline 4- 5 maanden & 4 & 76 & 6 & 77 \\
\hline 5- 6 maanden & 3 & 84 & 5 & 81 \\
\hline 6-7 maanden & 1 & 87 & 3 & 83 \\
\hline 7 - 8 maanden & 0 & 87 & 2 & 84 \\
\hline 8 - 9 maanden & 1 & 90 & 2 & 86 \\
\hline 9- 10 maanden & 2 & 95 & 2 & 87 \\
\hline 10 - 11 maanden & 1 & 97 & 1 & 88 \\
\hline 11 - 12 maanden & 1 & 100 & 1 & 89 \\
\hline $1-2$ jaar & & & 4 & 92 \\
\hline$>2$ jaar & & & 11 & 100 \\
\hline
\end{tabular}


hoofdomtrek (75\%); andere verwijsredenen waren ontwikkelingsachterstand, nystagmus en een lipoom. Slechts één patiënt was verwezen na het eerste levensjaar; dit was in verband met een ontwikkelingsachterstand.

\section{Discussie}

Het eerste doel van onze studie was te onderzoeken op welke leeftijd hydrocefalus in Nederland wordt ontdekt. De belangrijkste bevinding van onze studie is dat de meerderheid van de patiënten met hydrocefalus $(89 \%$; 95\%-BI: 82-93) wordt ontdekt in het eerste levensjaar. Deze bevindingen komen overeen met de conclusies van Zahl e.a. ${ }^{2}$ Het tweede doel was te onderzoeken welke rol hoofdomtrekmetingen spelen bij het ontdekken van hydrocefalus. Het lijkt alsof relatief weinig patiënten (31\%) met hydrocefalus worden verwezen vanwege een afwijkende hoofdomtrek. Voor de praktijk van de jeugdgezondheidszorg betekenen deze bevindingen dat routinematige hoofdomtrekmetingen beperkt kunnen blijven tot in het eerste levensjaar.

Onze resultaten zijn gebaseerd op de leeftijd bij verwijzing of (als deze niet bekend was) de leeftijd bij het eerste bezoek aan het WKZ of de start van de behandeling. Mogelijk zijn sommige kinderen wel ontdekt tijdens het eerste levensjaar, maar waren zij ouder dan 1 jaar bij het eerste bezoek aan het WKZ of de start van de behandeling. Dit zou kunnen leiden tot een mogelijke bias van onze resultaten. Als dit al het geval is, geeft het alleen maar meer steun aan de conclusie dat vrijwel alle kinderen met hydrocefalus in het eerste levensjaar worden ontdekt.

Een andere mogelijke reden voor bias is dat sommige kinderen met hydrocefalus gemist kunnen zijn, omdat zij een andere code of diagnose in het ziekenhuisinformatiesysteem kregen. We nemen aan dat dit niet gerelateerd zal zijn aan de leeftijd waarop de patiënten zijn gesignaleerd, daarom verwachten wij niet dat dit onze bevindingen en conclusie zal beïnloeden.

Het aantal gevonden patiënten dat is verwezen vanwege bijzonderheden in de hoofdomtrek zou mogelijk een onderschatting kunnen zijn. Van $24 / 146$ patiënten was de reden voor verwijzing niet genoteerd. Mogelijk is bij deze 24 patiënten ook de hoofdomtrek de reden voor verwijzing geweest.

Het percentage prematuur geboren patiënten in onze studiegroep is hoger dan in de algemene populatie (31\% versus $7 \%$ ). ${ }^{7}$ Dit kan worden verklaard door het feit dat cerebrale problemen die kunnen leiden tot hydrocefalus (zoals intraventriculaire bloedingen) vaker voorkomen bij prematuur geboren kinderen. Een groot deel van de patiënten met hydrocefalus was verwezen door de gynaecoloog op basis van de bevindingen tijdens echografisch onderzoek tijdens de zwangerschap. Met het toegenomen gebruik van echografie tijdens de zwangerschap is de verwachting dat kinderen met een hydrocefalus vaker prenataal gesignaleerd zullen gaan worden.
Het aantal kinderen dat was verwezen door de jeugdarts is relatief klein (19\%). Dit kan echter een onderschatting zijn. De jeugdarts verwijst kinderen naar de huisarts, en deze verwijst de kinderen vervolgens door naar een specialist. Dit was ten tijde van het onderzoek nog de gang van zaken, wat het veronderstelbaar maakt dat bij een deel van de kinderen bij wie de huisarts, de kinderarts of de neuroloog als eerste verwijzer was geregistreerd, wel degelijk de jeugdarts de ontdekking heeft gedaan. Nu de jeugdarts rechtstreeks kan verwijzen, wordt dit mogelijk anders.

Routinematige hoofdomtrekmetingen kunnen worden gebruikt om zowel macrocefalie als microcefalie op te sporen. Over de testeigenschappen van hoofdomtrekmetingen is echter nog niet zo veel bekend. Het is belangrijk dat er meer onderzoek gedaan wordt naar de sensitiviteit, specificiteit en voorspellende waarde van hoofdomtrekmetingen en de meest optimale verwijscriteria om pathologie op te sporen.

\section{Conclusie}

De meerderheid van de patiënten met hydrocefalus wordt ontdekt vóór het eerste levensjaar. Verder wordt hydrocefalus relatief weinig ontdekt op grond van een afwijkende hoofdomtrek in het eerste levensjaar. Daarom lijken hoofdomtrekmetingen weinig waarde te hebben voor de opsporing van hydrocefalus na het eerste levensjaar. Verder onderzoek is nodig om na te gaan wat de waarde is van routinematige metingen, en of deze metingen leiden tot vroege signalering van pathologie en verbetering van de prognose.

\section{Literatuur}

1. Garne E, Loane M, Addor MC, Boyd PA, Barisic I, Dolk H. Congenital hydrocephalus - prevalence, prenatal diagnosis and outcome of pregnancy in four European regions. Eur J Paediatr Neurol. 2010;14:150-5.

2. Zahl SM, Wester K. Routine measurement of head circumfe rence as a tool for detecting intracranial expansion in infants: what is the gain? A nationwide survey. Pediatrics. 2008;121:e416-20.

3. Fredriks AM, Buuren S van, Burgmeijer RJ, Meulmeester JF, Beuker RJ, Brugman E, e.a. Continuing positive secular growth change in the Netherlands 1955-1997. Ped Research 2000;47:316-23

4. Daymont C, Zabel M, Feudtner C, Rubin DM. The test characteristics of head circumference measurements for pathology associated with head enlargement: a retrospective cohort study. BMC Pediatrics. 2012;12:9-18.

5. Department of Health SSaPS. Health for all children 4. Guidance \& principles of practice for professional staff. 2004.

6. Vlaamse Wetenschappelijke Vereniging voor Jeugdgezondheidszorg (VWVJ). Standaard 'Groel en Pubertaire ontwikke ling'. 2005

7. European Perinatal Health Report. [Internet] Geraadpleegd op 10 september 2012. Beschikbaar via: www.europeristat.com 